\title{
Effective Efficiency Evaluation for Solar Air Heater using Different Artificial Coarseness
}

\section{Gaurav Bharadwaj ${ }^{1}$}

${ }^{1}$ Assistant Professor, Department of Mechanical Engineering, GLA University, Mathura gauravmech2211@gmail.com; gaurav.bhardwaj@gla.ac.in ${ }^{1}$

Article History: Received: 10 November 2020; Revised: 12 January 2021; Accepted: 27 January 2021; Published online: 05 April 2021

Abstract: Effective efficiency evaluation is one of the important parameters in designing and selection of SAH. In this research article author have evaluated the effective efficiency of SAH using different coarseness configuration attached to the underside of collector of SAH used by various research. Correlation developed by various researchers for various coarseness has been used for the evaluation of effective efficiency. Effective efficiency evaluated for each coarseness used in SAH has been compared and suggested that which coarseness is to be used on the basis of comparison.

Keywords: Effective efficiency, SAH, Coarseness, Collector, Parameters

\section{Introduction}

In today's era, need of energy is growing steadily with growing population rate of the world. We have only the limited sources of energy like fossil fuels, Nuclear fuels, Renewable energy sources, etc. Need of most of the energy requirement is fulfilled by fossil fuels and the generation of energy using fossil fuels creates a lot of pollution and the availability of fossil fuels is limited and will be vanished with its continuous use of it. In short, we can say that using fossil fuel for energy generation is destroying life on the planet Earth. So, we have to think to switch to other energy sources that are eco-friendly. Only sources of energy that are eco-friendly are Renewable energy sources. We are using renewable energy sources like Solar energy, wind energy, biogas, etc but their uses are limited as compared to the need of energy. We have to increase the uses of renewable energy sources for energy generation to prevent the planet Earth as well as on the other hand cost of energy generation by using renewable energy sources is very less as compared to energy generation by fossil fuels. There is one dominating source of energy which is renewable and can fulfil the need of energy all alone i.e., Solar energy if it is properly used Duffie and Beckman [1]. Solar energy can be utilized to generate electricity using PV Cells. Solar energy can also be used to heat air and water by transferring the energy to the working fluid. For this purpose, SAH and SWH are available, Mittal et al. [2]. Designing SAH as compared to SWH is easy and economical but there is a limitation with SAH. The efficiency of SAH is quite low due to the low heat carrying capacity of air and low heat transfer between the collector plate and air. There is only one possible way suggested by number of researchers to increase the efficiency of SAH is the creation of artificial coarseness on the underside of the collector plate. Due to the creation of coarseness the laminar sub layer on the collector plate gets destroyed and hence the heat transfer rate between the collector plate and air get augmented. Coarseness is created in such a way that it augments the heat transfer with minimum pumping power. Coarseness can be created by using ribs, machining, etc Hans et al. [3]; Saini et al. [4]; Bhushan and Singh [5].

The consequence of using coarseness on heat transfer and friction factor to the two opposite surfaces of the SAH duct has been investigated by Zhang et al. [6]; Han et al. [7]. In case of SAH, the coarseness must be created just underneath the collector plate receiving solar radiations. Therefore, a rectangular channel with one coarse wall and three smooth walls is built for SAH. It has been seen during the literature review that many investigators have used Reynolds number as flow parameter and coarseness parameter like p/e, e/D, $\alpha$, etc.

\section{Concept of Coarseness Creation}

Nikuradse et al. [8] was the first investigator who had seen the consequence of coarseness on the friction factor and velocity distribution created by sand blasting in the pipes. In simple words we can say that Nikuradse has proposed the concept of using roughness to augment the heat transfer. After Nikuradse et al. [8], Dippery and Sabersky [9] was the researchers who have seen the consequence of using coarseness in the tubes created by sand grain. They have developed the correlation for finding heat transfer in coarse tubes. Later on, Gee and Webb [10] investigated the consequence of using helical ribs in the tube to enhance the heat transfer and friction factor. They also developed the correlation for heat transfer in terms of coarseness variable. Further, investigation has been carried out by number of investigators to see the consequence of using coarseness in the SAH duct. They have carried out the study by using various range of operating parameters and coarseness 
parameter to see the consequence on heat transfer and friction factor. Experimental data collected on various geometries of rib roughened surfaces has been utilized for development of correlation of the form:

$\mathrm{R}=\mathrm{R}(\mathrm{Re}, \mathrm{p} / \mathrm{e}, \alpha$, channel shape, rib shape)

$\mathrm{G}=\mathrm{G}(\mathrm{Re}, \mathrm{p} / \mathrm{e}, \alpha$, channel shape, rib shape)

It was however, subsequently realized that the statistical correlations may be better suited for design and easy to formulate. Such relationship can be of the form:

$\mathrm{Nu}$ or $(\mathrm{St})=\mathrm{Nu}$ or $(\mathrm{St})[\mathrm{Re}, \mathrm{e} / \mathrm{D}, \mathrm{p} / \mathrm{e}, \alpha$, rib shape, channel shape]

$\mathrm{f}=[\mathrm{Re}, \mathrm{e} / \mathrm{D}, \mathrm{p} / \mathrm{e}, \alpha$, rib shape, channel shape $]$

\subsection{Consequence of coarseness Variable and Flow variable on heat transfer and friction factor}

The consequence of coarseness on heat transfer and friction factors has been investigated by various investigators. The correlations for the Nusselt number and the friction factor were also established as a result of the flow variables and coarseness variable. Prasad and Saini [11] have seen the consequence of coarseness variable like dimensionless coarseness height (e/D) and dimensionless coarseness pitch (P/E) on the heat transfer and friction factor. They have suggested that the value of e/D and p/e must be in the range of 0.033 and 10 so as to augment the heat transfer and friction factor in SAH duct. Momin et. al. [12] have carried ot an investigation to see the consequence of using continuous V-shaped ribs to the underside of collector plate. The maximal augmentation of $\mathrm{Nu}$ and friction factor was reported to be 2.30 and 2.83 folds, respectively for $\alpha$ of $60^{\circ}$. Lanjewar et. al. [13] have investigated the consequence of using $\mathrm{W}$ shaped ribs attached to the underside of collector plate. They found that enhancement in $\mathrm{Nu}$ and friction factor was 2.36 and 2.01 folds, respectively. Kumar et. al. [14]; Shukla and Sharma [15] investigated the consequence of using discrete W shape ribs to the underside of collector plate. The maximal augmentation in $\mathrm{Nu}$ and friction factor was reported to be respectively 2.16- and 2.75-folds w.r.t $\alpha$ of $60^{\circ}$. Saini and Saini [16] investigated the consequence of using continuous arc shape ribs to the underside of collector plate. The maximal augmentation in $\mathrm{Nu}$ and friction factor was reported to be respectively 3.80 and 1.75 folds w.r.t $\alpha$ of $60^{\circ}$. Sethi et. al. [17] investigated the consequence of using dimple-shape coarseness arranged in arc fashion to the underside of collector plate. They also evaluated the thermohydraulic performance variable that lies in between 1.18 to 1.887. Yadav et. al. [18] investigated the consequence of using hemi-spherical protrusion in arc shape to the underside of collector plate. The maximal augmentation in heat transfer and friction factor was observed to be 2.89 and 2.93 folds respectively. Deo et. al. [19]; Kumar and Sharma [20] examined the consequence of using multi-gap V down ribs amalgated with staggered ribs to the underside of collector plate. The maximal augmentation in $\mathrm{Nu}$, friction factor and thermohydraulic performance variable was reported to be 3.34, 3.38 and 2.45 times respectively. Correlations for $\mathrm{Nu}$ and friction factor developed by various researchers have been shown in Table 1. These correlations are used for evaluation of effective efficiency and their comparison.

Table 1. Parameters and Correlation developed by various researchers

\begin{tabular}{|c|c|c|c|}
\hline $\begin{array}{l}\text { Investigator } \\
\mathrm{S}\end{array}$ & $\begin{array}{l}\text { Coarseness } \\
\text { configuratio } \\
\text { n }\end{array}$ & $\begin{array}{l}\text { Range of } \\
\text { parameter } \\
\text { S }\end{array}$ & Correlations \\
\hline $\begin{array}{ll}\text { Momin et. } \\
\text { al. [12] }\end{array}$ & \begin{tabular}{l}
\multicolumn{2}{l}{ Continuous } \\
V- shaped \\
ribs
\end{tabular} & $\begin{array}{l}\mathrm{Re}=2500- \\
18000 \\
\mathrm{p} / \mathrm{e}=10 \\
\mathrm{e} / \mathrm{D}_{\mathrm{h}}= \\
0.02-0.034 \\
\alpha=30^{\circ}- \\
90^{\circ}\end{array}$ & $\begin{array}{l}N u=0.067 \times \operatorname{Re}^{0.888}\left(\frac{\alpha}{60}\right)^{-0.077}\left(\frac{e}{D_{h}}\right)^{0.424} \exp \left[-0.782\left\{\ln \left(\frac{\alpha}{60}\right)\right\}^{2}\right] \\
f=6.266 \times \operatorname{Re}^{-0.425}\left(\frac{\alpha}{60}\right)^{-0.093}\left(\frac{e}{D_{h}}\right)^{0.565} \exp \left[-0.719\left\{\ln \left(\frac{\alpha}{60}\right)\right\}^{2}\right]\end{array}$ \\
\hline $\begin{array}{l}\text { Lanjewar et. } \\
\text { al. [13] }\end{array}$ & $\begin{array}{l}\text { W-shaped } \\
\text { ribs }\end{array}$ & $\begin{array}{l}\operatorname{Re}=2300- \\
14000 \\
\mathrm{p} / \mathrm{e}=10 \\
\mathrm{e} / \mathrm{D}_{\mathrm{h}}=0.018 \\
-0.03375 \\
\alpha=30^{\circ} \\
75^{\circ}\end{array}$ & $\begin{array}{l}N u=0.0613 \times \operatorname{Re}^{0.9079}\left(\frac{e}{D_{h}}\right)^{0.4487}\left(\frac{\alpha}{60}\right)^{-0.1331} \\
\exp \left[-0.5307\left\{\ln \left(\frac{\alpha}{60}\right)\right\}^{2}\right]\end{array}$ \\
\hline
\end{tabular}




\begin{tabular}{|c|c|c|c|}
\hline & & & $\begin{array}{l}f=0.6182 \times \operatorname{Re}^{-0.2254}\left(\frac{e}{D_{h}}\right)^{0.4622}\left(\frac{\alpha}{60}\right)^{-0.0817} \\
\exp \left[-0.28\left\{\ln \left(\frac{\alpha}{60}\right)\right\}^{2}\right]\end{array}$ \\
\hline $\begin{array}{l}\text { Kumar et. al. } \\
\text { [14] }\end{array}$ & $\begin{array}{l}\text { Discrete W- } \\
\text { shaped ribs }\end{array}$ & $\begin{array}{l}\mathrm{Re}=3000- \\
15000 \\
\mathrm{p} / \mathrm{e}=10 \\
\mathrm{e} / \mathrm{D}_{\mathrm{h}}=0.016 \\
8-0.0338 \\
\alpha=30^{\circ} \\
75^{\circ}\end{array}$ & $\begin{array}{l}N u=0.105 \times \operatorname{Re}^{0.873}\left(\frac{e}{D_{h}}\right)^{0.453}\left(\frac{\alpha}{60}\right)^{-0.081} \exp \left[-0.59\left\{\ln \left(\frac{\alpha}{60}\right)\right\}^{2}\right] \\
f=5.68 \times \operatorname{Re}^{-0.40}\left(\frac{e}{D_{h}}\right)^{0.59}\left(\frac{\alpha}{60}\right)^{-0.081} \exp \left[-0.579\left\{\ln \left(\frac{\alpha}{60}\right)\right\}^{2}\right]\end{array}$ \\
\hline $\begin{array}{l}\text { Saini and } \\
\text { Saini [15] }\end{array}$ & shape & $\begin{array}{l}\mathrm{Re}=2000- \\
17000 \\
\mathrm{p} / \mathrm{e}=10 \\
\mathrm{e} / \mathrm{D}=0.021 \\
3-0.0422 \\
\alpha=30^{\circ}- \\
75^{\circ}\end{array}$ & $\begin{array}{l}N u=0.001047 \times \operatorname{Re}^{1.3186}\left(\frac{e}{D}\right)^{0.3772}\left(\frac{\alpha}{90}\right)^{-0.1198} \\
f=0.14408 \times \operatorname{Re}^{-0.17103}\left(\frac{e}{D}\right)^{0.1765}\left(\frac{\alpha}{90}\right)^{0.1185}\end{array}$ \\
\hline $\begin{array}{l}\text { Sethi et. al. } \\
\text { [16] }\end{array}$ & $\begin{array}{l}\text { Arc shape } \\
\text { dimple } \\
\text { arrangement }\end{array}$ & $\begin{array}{l}\operatorname{Re}=3600- \\
18000 \\
\mathrm{p} / \mathrm{e}=10-20 \\
\mathrm{e} / \mathrm{D}_{\mathrm{h}}=0.021 \\
-0.036 \\
\alpha=45^{\circ} \\
75^{\circ}\end{array}$ & $\begin{array}{l}N u=7.1 \times 10^{-3} \times \operatorname{Re}^{1.1386}\left(\frac{e}{D_{h}}\right)^{0.3629}\left(\frac{p}{e}\right)^{-0.047}\left(\frac{\alpha}{60}\right)^{-0.0048} \\
\exp \left[-0.7792\left\{\ln \left(\frac{\alpha}{60}\right)\right\}^{2}\right] \\
f=4.869 \times 10^{-1} \times \operatorname{Re}^{-0.223}\left(\frac{e}{D_{h}}\right)^{0.2663}\left(\frac{p}{e}\right)^{-0.059}\left(\frac{\alpha}{60}\right)^{-0.0042} \\
\exp \left[-0.4801\left\{\ln \left(\frac{\alpha}{60}\right)\right\}^{2}\right]\end{array}$ \\
\hline $\begin{array}{l}\text { Yadav et. al. } \\
\text { [17] }\end{array}$ & $\begin{array}{l}\text { Hemi- } \\
\text { spherical } \\
\text { protrusion } \\
\text { arranged in } \\
\text { arc shape }\end{array}$ & $\begin{array}{l}\mathrm{Re}=3600- \\
18100 \\
\mathrm{p} / \mathrm{e}=12-24 \\
\mathrm{e} / \mathrm{D}=0.015- \\
0.03 \\
\alpha=45^{\circ} \\
75^{\circ}\end{array}$ & $\begin{array}{l}N u=0.154 \times \operatorname{Re}^{1.017}\left(\frac{e}{D}\right)^{0.521}\left(\frac{p}{e}\right)^{-0.38}\left(\frac{\alpha}{60}\right)^{-0.213} \\
\exp \left[-2.023\left\{\ln \left(\frac{\alpha}{60}\right)\right\}^{2}\right] \\
f=7.207 \times \operatorname{Re}^{-0.56}\left(\frac{e}{D}\right)^{0.176}\left(\frac{p}{e}\right)^{-0.18}\left(\frac{\alpha}{60}\right)^{0.038} \\
\exp \left[-1.412\left\{\ln \left(\frac{\alpha}{60}\right)\right\}^{2}\right]\end{array}$ \\
\hline $\begin{array}{lll}\text { Deo } & \text { et. } & \text { al } \\
{[18]} & & \end{array}$ & $\begin{array}{l}\text { multi-gap } \mathrm{V} \\
\text { down ribs } \\
\text { combined } \\
\text { with }\end{array}$ & $\begin{array}{l}\mathrm{Re}=4000- \\
12000 \\
\mathrm{p} / \mathrm{e}=4-14 \\
\mathrm{e} / \mathrm{D}_{\mathrm{h}}=\end{array}$ & $N u=0.02253 \times \operatorname{Re}^{0.98}\left(\frac{e}{D_{h}}\right)^{0.18}\left(\frac{p}{e}\right)^{-0.06}\left(\frac{\alpha}{60}\right)^{0.04}$ \\
\hline
\end{tabular}




\begin{tabular}{|l|l|l|l|}
\hline staggered & $0.026-$ & \\
ribs & 0.057 \\
& $\alpha=40^{\circ}-$ & $f=0.37156 \times \mathrm{Re}^{-0.15}\left(\frac{e}{D_{h}}\right)^{0.65}\left(\frac{p}{e}\right)^{0.21}\left(\frac{\alpha}{60}\right)^{0.57}$ \\
& $80^{\circ}$ & \\
& $\mathrm{w} / \mathrm{e}=4.5$ \\
& $\mathrm{p} / \mathrm{P}=0.65$ & \\
& $\mathrm{~g} / \mathrm{e}=1$ \\
& $\mathrm{n}=2$ & \\
& &
\end{tabular}

\section{Evaluation of Effective efficiency in SAH}

Hottel and Woertz were the first to evaluate the thermal performance of flat plate solar collector in terms of heat removal factor (Fr) as reported by Duffie and Beckman [1]. Useful energy gain (Qu) as a function of inlet temperature of the fluid ( $\mathrm{Ti}$ ) and the ambient temperature (Ta) as reported by Duffie and Beckman [1] is given as:

Useful energy gain $Q_{u}=F_{r} A_{P}\left[I(\tau \alpha)-U_{L}\left(T_{i}-T_{a}\right)\right]$

Useful energy gain can also be expressed in terms of increase in enthalpy of air through the collect.

Useful energy gain $Q_{u}=m C_{p}\left(T_{o}-T_{i}\right)$

By comparing eq. (1) and eq. (2), heat removal factor can be written as,

$$
F_{r}=\frac{m C_{p}\left(T_{o}-T_{i}\right)}{A_{p}\left[I(\tau \alpha)-U_{L}\left(T_{i}-T_{a}\right)\right]}
$$

Thermal efficiency of SAH is the ratio of useful energy gain to the solar irradiance and can be given as Duffie and Beckmen [1].

$$
\eta_{t h}=\frac{Q_{u}}{A_{p} I}=F_{r}\left[(\tau \alpha)-U_{L}\left(\frac{T_{i}-T_{a}}{I}\right)\right]
$$

Effective efficiency has been evaluated for the various coarseness configuration used by various researcher. The typical values of variable taken into consideration for determining effective efficiency are given in Table 2 .

Table 2. Typical values of system and operating variables

\begin{tabular}{|l|l|}
\hline Variables & Values \\
\hline System variables & \\
\hline Collector length, $\mathrm{L}$ & $1 \mathrm{~m}$ \\
\hline Duct width, $\mathrm{W}$ & $0.2 \mathrm{~m}$ \\
\hline Duct height, $\mathrm{H}$ & $0.02 \mathrm{~m}$ \\
\hline Overall loss coefficient, $\mathrm{U}_{\mathrm{L}}$ & $10 \mathrm{~W} / \mathrm{m}^{2} \mathrm{~K}$ \\
\hline Thermal conductivity of insulation, $\mathrm{k}$ & $0.0262 \mathrm{~W} / \mathrm{mK}$ \\
\hline Transmittance-absorptance product, $\tau \alpha$ & 0.85 \\
\hline Dimensionless coarseness height, $\mathrm{e} / \mathrm{D}$ & 0.045 \\
\hline Dimensionless coarseness pitch, $\mathrm{p} / \mathrm{e}$ & 12 \\
\hline Reynolds number, Re & $3000-27000$ \\
\hline Angle of Attack, $\alpha$ & $30^{\circ}-75^{\circ}$ \\
\hline Operating variables & \\
\hline Ambient temperature, $\mathrm{T}_{\mathrm{a}}$ & $300 \mathrm{~K}$ \\
\hline Wind velocity, $\mathrm{V}$ & $1 \mathrm{~m} / \mathrm{s}$ \\
\hline Solar radiation intensity, I & \multicolumn{1}{|c|}{10002} \\
\hline
\end{tabular}




\section{Result and Discussions}

Evaluation of effective efficiency has been done on the basis of the method proposed by Duffie and Beckman [1]. It has been examined during the literature review that there are three important coarseness variable and one flow variable that are e/D, p/e, $\alpha$ and Re respectively. During the investigation value of e/D and $\mathrm{p} / \mathrm{e}$ are kept constant as in many studies it has been seen that maximal enhancement in heat transfer occur at e/D of 0.045 and $\mathrm{p} / \mathrm{e}$ of 12. Effect of increasing $\alpha$ and Re on effective efficiency has been investigated using different coarseness configuration. Fig. 1 to Fig. 7 has shown the variation of effective efficiency w.r.t Re. It has been seen from Fig. 1 to Fig. 7 that effective efficiency goes on increasing upto Re 18000 and after it there is a gradual decrease in effective efficiency. This is due to the reason that at higher Re pumping power required will be more. It can also be seen from the Fig. 1 to Fig. 7 that maximum effective efficiency is obtained at angle of attack 60deg. This is because of the Span wise anti rotating secondary flows created by inclination of the rib that is responsible for the significant span wise variation in the coefficient of heat transfer.

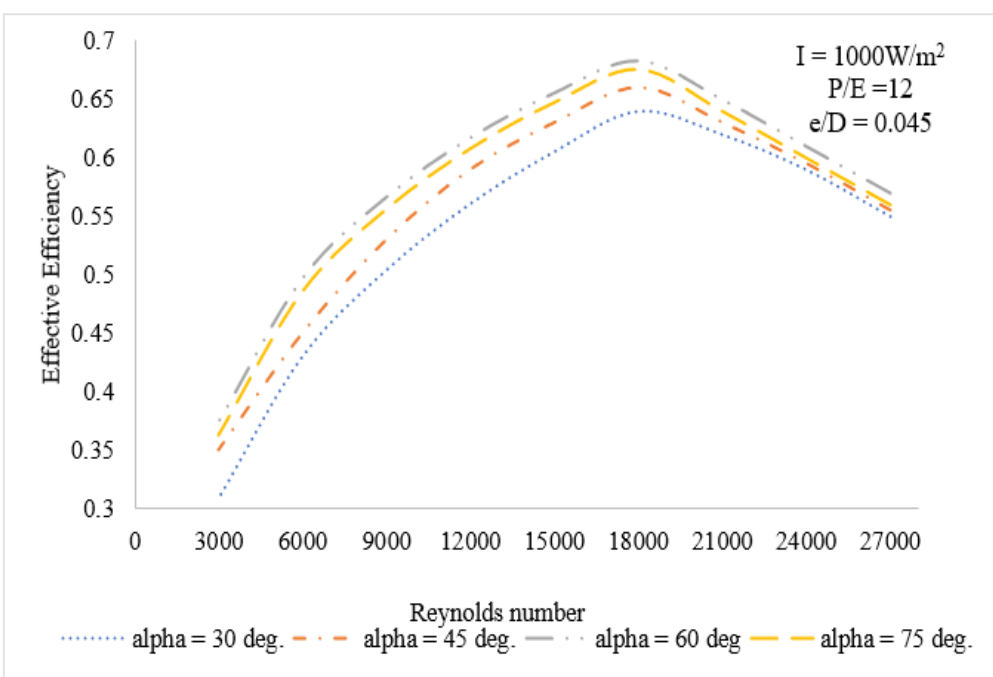

Figure 1. Variation in Effective efficiency w.r.t Reynolds number for the configuration used by Momin et. al. [12]

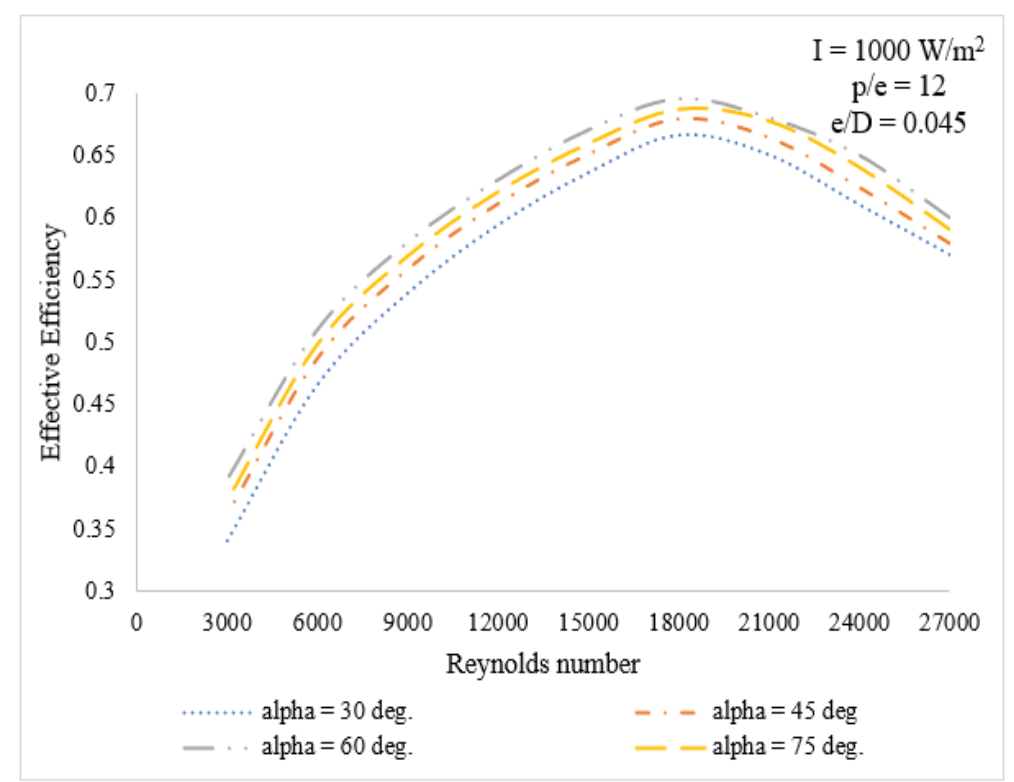

Figure 2. Variation in Effective efficiency w.r.t Reynolds number for the configuration used by Lanjewar et. al.

[13] 


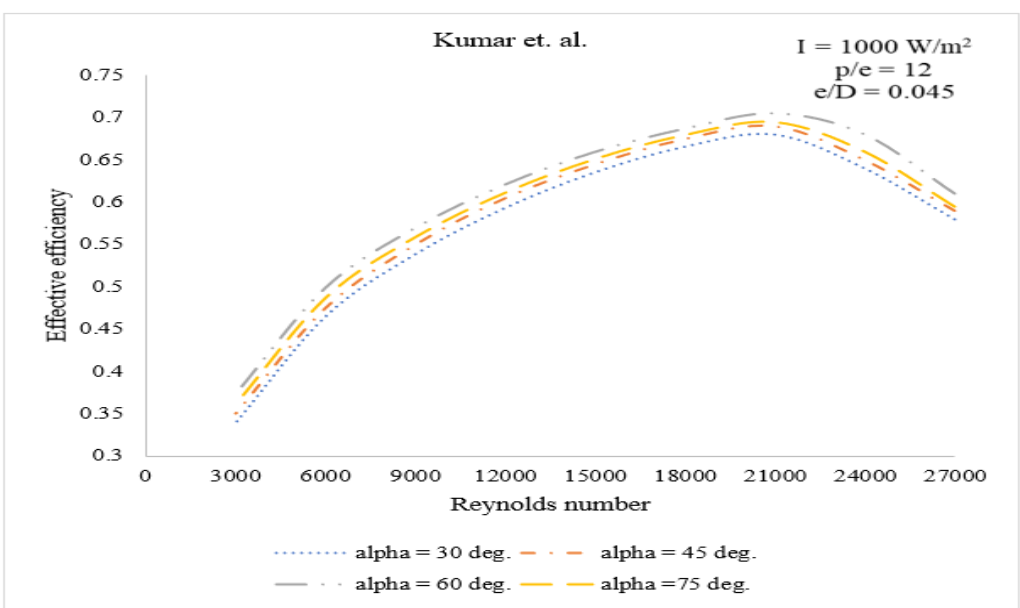

Figure 3. Variation in Effective efficiency w.r.t Reynolds number for the configuration used by Kumar et. al.

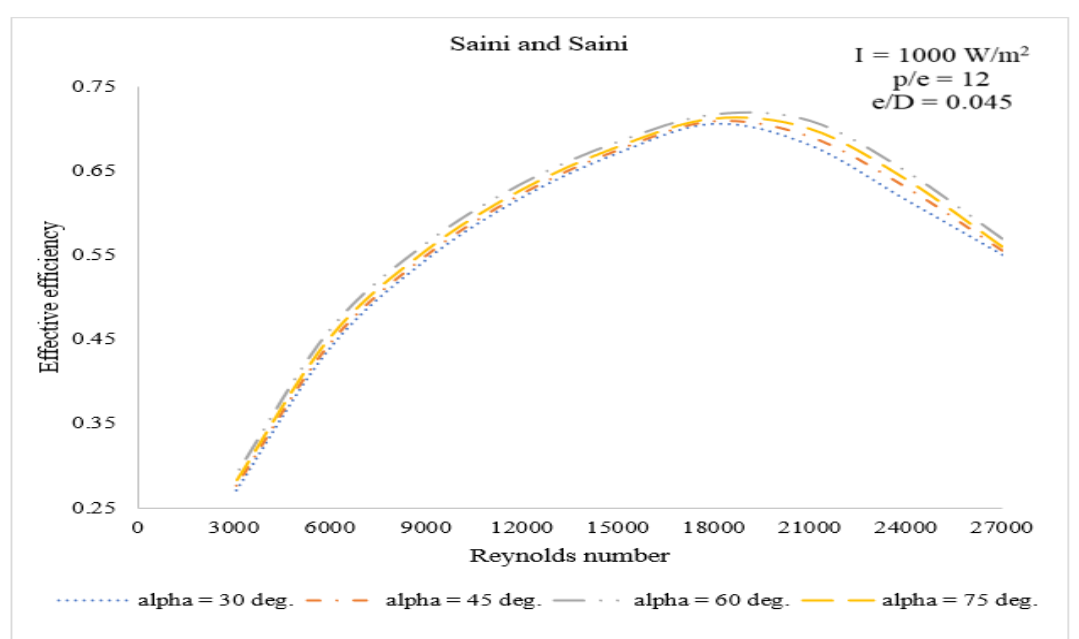

Figure 4. Variation in Effective efficiency w.r.t Reynolds number for the configuration used by Saini and Saini [15]

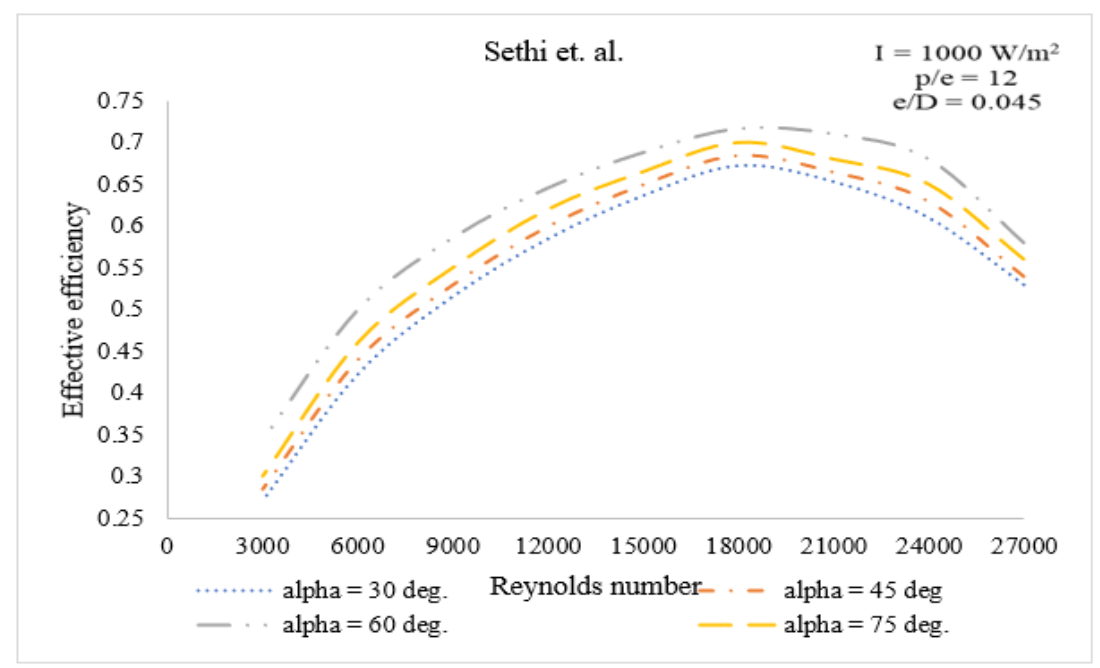

Figure 5. Variation in Effective efficiency w.r.t Reynolds number for the configuration used by Sethi et. al. [16] 


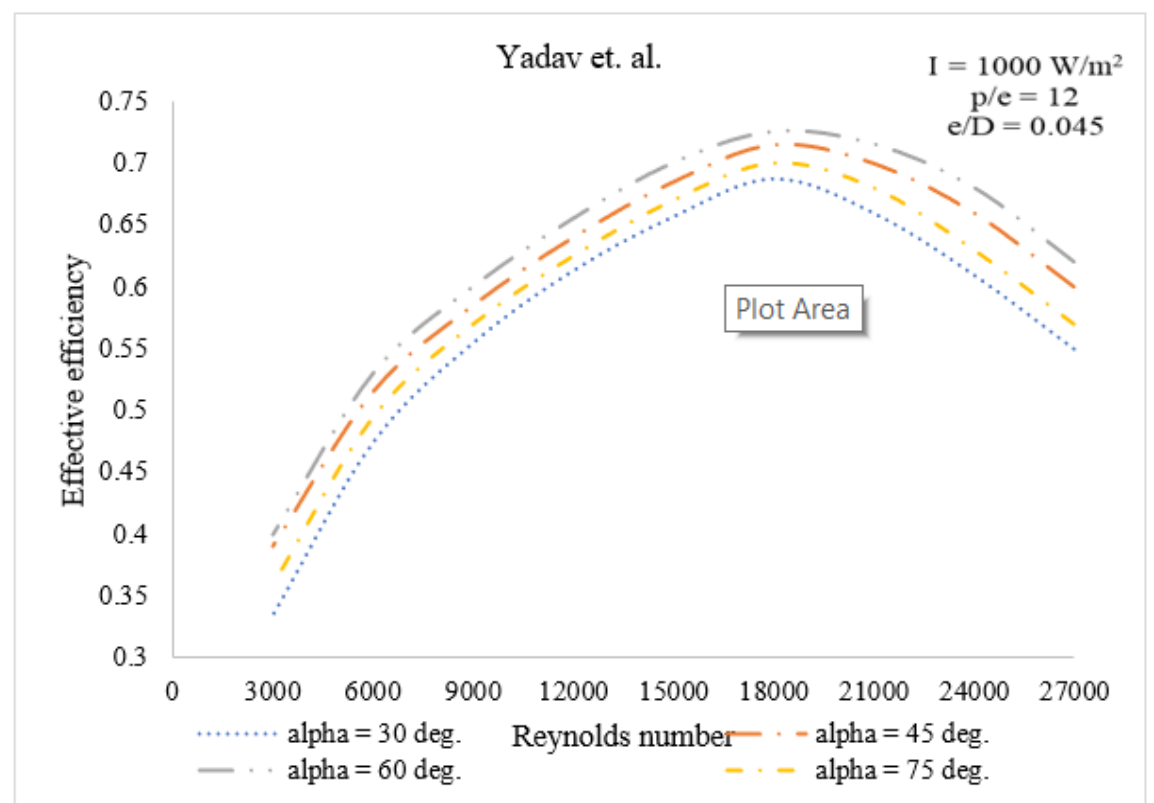

Figure 6. Variation in Effective efficiency w.r.t Reynolds number for the configuration used by Yadav et. al. [17]

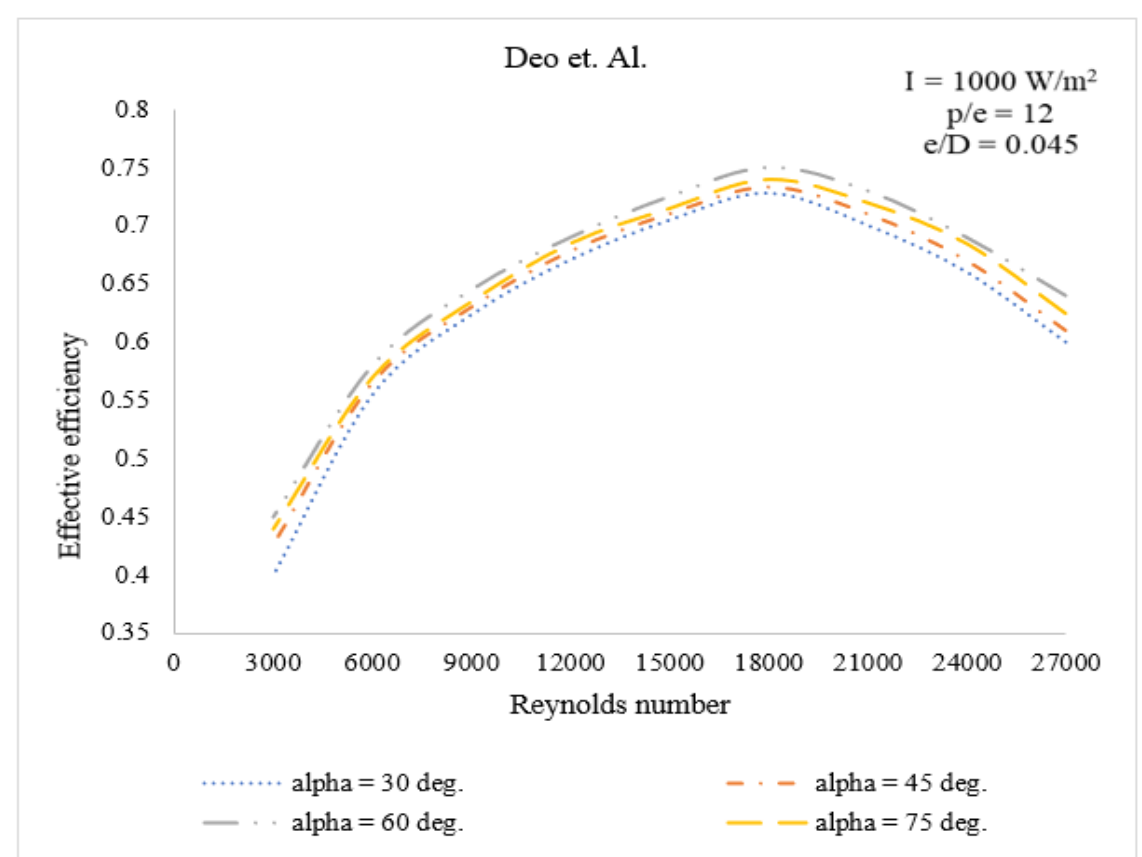

Figure 7. Variation in Effective efficiency w.r.t Reynolds number for the configuration used by Deo et. al. [18]

Fig. 8 shows the comparison of effective efficiency w.r.t Reynolds number for various configurations used by number of investigators. It can be clearly seen from Fig 8. that effective efficiency is higher in all configuration up to the Reynolds number 18000 and after Re 18000 effective efficiency starts decreasing. Out of all the configuration the highest effective efficiency is evaluated for Deo et. al. [18]. It means that out of all the configuration the enhancement in the heat transfer and friction factor is more by using multigap V-down ribs combined with staggered ribs as coarseness attached to the underside of the collector plate for full range of Reynolds number. 


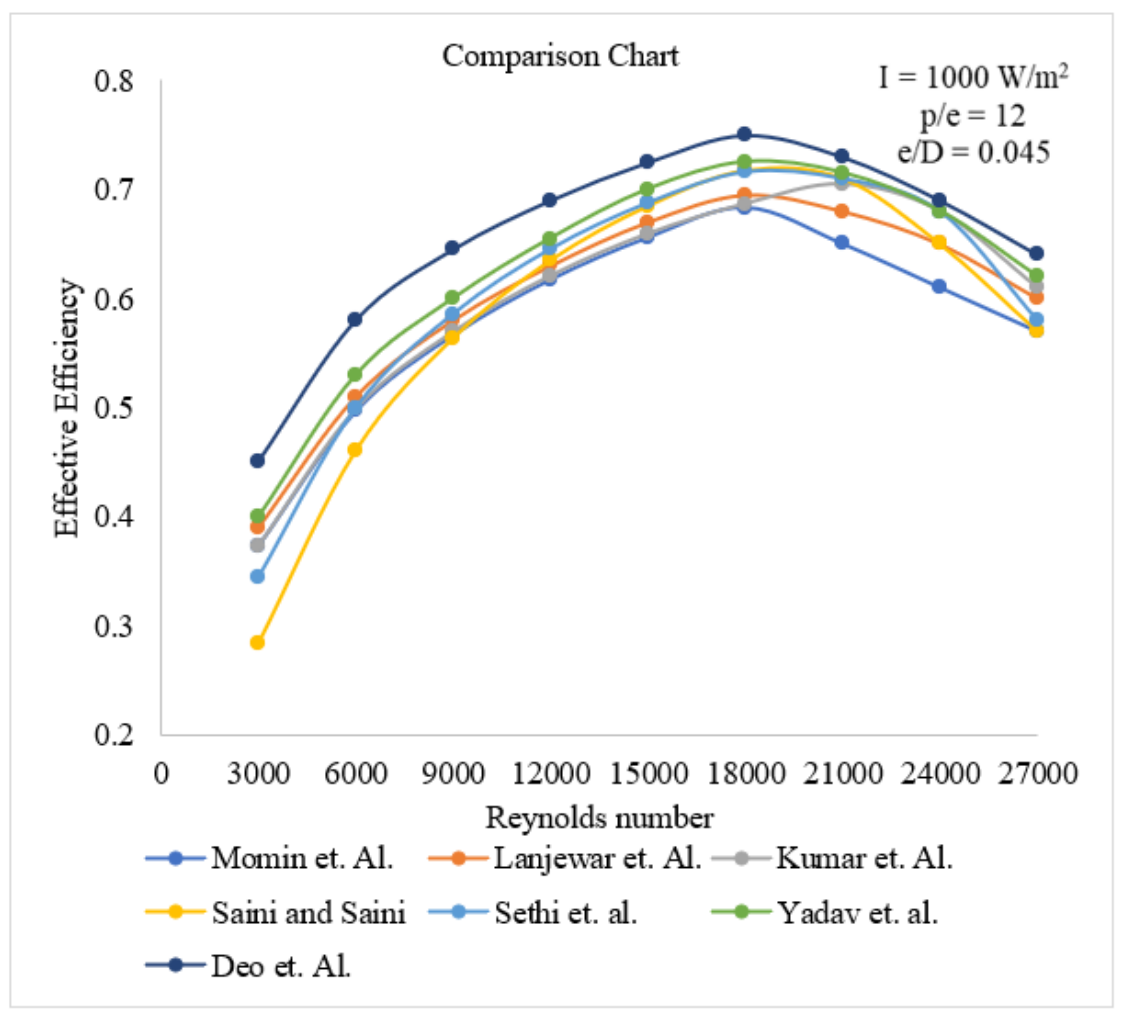

Figure 8. Variation in Effective efficiency w.r.t Reynolds number for the various configurations used by various investigators at $\alpha=60 \mathrm{deg}, \mathrm{e} / \mathrm{D}=0.045$ and $\mathrm{p} / \mathrm{e}=12$

\section{Conclusion}

In this article an effort has been made to evaluate the effective efficiency of various configurations of coarseness attached to the underside of the collector plate of SAH in order to increase heat transfer and friction factor. Following conclusions can be drawn from this work:

1. Augmentation in the heat transfer and friction factor is achieved by using coarseness attached to the underside of collector plate.

2. Effective efficiency has been evaluated using correlation proposed by various coarseness configuration used by various investigators.

3. Maximal effective efficiency is obtained at Reynolds number 18000 for every coarseness configuration and it further start decreasing with increasing Reynolds number.

4. Maximal effective efficiency has been found at angle of attack $\alpha=60 \mathrm{deg}$.

5. Maximal effective efficiency has been found by using multigap V-down ribs combined with staggered ribs as coarseness for the full range of Reynolds number.

\section{Future Scope}

Enhancement can also be achieved by improving the absorptivity of collector plate by coating it with different nano particle as used by various researchers.

\section{Nomenclature}

SAH: Solar Air Heater

SWH: Solar water heater

e+: coarseness Reynolds number

Re: Reynolds number

$\operatorname{Re}(\mathrm{e}+)$ : Momentum transfer function

f: Friction factor

e/D: Dimensionless coarseness height

p/e: Dimensionless coarseness pitch 
W: Width of channel, mm $\mathrm{H}$ : Height of channel, $\mathrm{mm}$ qu: useful heat flux, W/m2 FR: Heat removal factor UL: Overall heat loss coefficient, W/m2K

Ti: Inlet temperature, $\mathrm{K}$

Ta: Ambient temperature, $\mathrm{K}$

To: Outlet temperature, $\mathrm{K}$

$\Delta \mathrm{P}$ : Pressure drop, $\mathrm{Pa}$

\section{Greek symbols}

$\eta$ th: Effective efficiency

$\rho$ : Density, $\mathrm{kg} / \mathrm{m} 3$

$\alpha$ : Angle of attack or arc angle, degree

\section{References}

1. Duffie, J.A., Beckman, W.A., "Solar Engineering of Thermal Processes", Wiley Inter science publications, New York, Vol. 3, 1980.

2. Mittal, M.K., Saini, R.P. and Singal, S.K., "Effective efficiency of solar air heaters having different types of roughness elements on the absorber plate". Journal of Energy, Vol. 32, no.5, pp.739-745, 2007.

3. Hans, V. S., Saini, R. P., \& Saini, J. S., "Performance of artificially roughened solar air heatersA review", Renewable and Sustainable Energy Reviews, Vol.13, no.8, pp.1854-1869, 2009.

4. Saini, R. P., Singal S. K., "A review on roughness geometry used in solar air heaters", Solar energy, Vol.81, no.11, pp. 1340-1350, 2007.

5. Bhushan, B., \& Singh, R., "A review on methodology of artificial roughness used in duct of solar air heaters", Energy, Vol. 35, no.1, pp.202-212, 2010

6. Zhang, Y., Gu, W., \& Xu, H., "Enhancement of heat transfer and flow drag in roughened rectangular passages", JETh, Vol. 5, pp.275-280, 1984.

7. Han, J.C., Glicksman, L.R. and Rohsenow, W.M., "An investigation of heat transfer and friction for rib-roughened surfaces", International Journal of Heat and Mass Transfer, Vol.21, no.8, pp.1143-1156, 1978.

8. Nikuradse, J., "Laws of flow in rough pipes", Washington: National Advisory Committee for Aeronautics, Vol. 2, 1950.

9. Dipprey, D.F. and Sabersky, R.H., "Heat and momentum transfer in smooth and rough tubes at various Prandtl numbers", International Journal of Heat and Mass Transfer, Vol.6, no.5, pp.329353, 1963

10. Gee, D.L. and Webb, R.L., "Forced convection heat transfer in helically rib-roughened tubes", International Journal of Heat and Mass Transfer, Vol.23, no.8, pp.1127-1136, 1980

11. Prasad, B.N., Saini, J.S., "Effect of artificial roughness on heat transfer and friction factor in a solar air heater", Solar Energy, Vol.4, no.6, pp.555-560, 1988.

12. Ebrahim, Momin AM., Saini, JS., Solanki, SC., "Heat transfer and friction in solar air heater duct with V-shaped rib roughness on absorber plate", Int J Heat Mass Transfer; Vol. 45, pp.3383-3396, 2002.

13. Lanjewar A, Bhagoria JL, Sarviya RM,. "Heat transfer and friction in solar air heater duct with Wshaped rib roughness on absorber plate", Energy, Vol. 36, pp.4531-4, 2011.

14. Kumar, A., Bhagoria, J.L. and Sarviya, R.M., "Heat transfer and friction correlations for artificially roughened solar air heater duct with discrete W-shaped ribs", Energy Conversion and management, Vol.50, no.8, pp.2106-2117, 2009

15. Shukla, M.K. and K. Sharma, "Improvement in mechanical and thermal properties of epoxy hybrid composites by functionalized graphene and carbon-nanotubes", Materials Research Express, Vol. 6, no.12, pp. 125323, 2019.

16. Saini, S.K. and Saini, R.P., "Development of correlations for Nusselt number and friction factor for solar air heater with roughened duct having arc-shaped wire as artificial roughness". Solar Energy, Vol.82, no.12, pp.1118-1130, 2008.

17. Sethi, M. and Thakur, N.S., "Correlations for solar air heater duct with dimpled shape roughness elements on absorber plate”, Solar Energy, Vol.86, no.9, pp.2852-2861, 2012. 
18. Yadav, S. and Kaushal, M., "Nusselt number and friction factor correlations for solar air heater duct having protrusions as roughness elements on absorber plate", Exp. Therm. Fluid Sci, Vol.44, pp.34-41, 2013.

19. Deo, N. S., Chander, S., \& Saini, J. S., "Performance analysis of solar air heater duct roughened with multigap V-down ribs combined with staggered ribs", Renewable Energy, Vol.91, pp.484500, 2016.

20. A. Kumar, K. Sharma, AR. Dixit., "Carbon nanotube-and graphene-reinforced multiphase polymeric composites, Review on their properties and applications", Journal of Materials Science, Vol.55, no.7,pp. 2682-2724, 2020 